Pak. j. sci. ind. res. Ser. A: phys. sci. 2021 64A(1) 19-25

\title{
Phase, Microstructural Characterization and Beneficiation of Iron Ore by Shaking Table
}

\author{
Sajad Ali*, Fahad Nawaz and Yaseen Iqbal \\ Materials Research Laboratory, Department of Physics, University of Peshawar, Peshawar-25120, Pakistan
}

(received Feburary 25, 2019; revised June 20, 2019; accepted July 2, 2019)

\begin{abstract}
To know about the nature of gangue associated with the ores, characterization has become an integral part in mineral processing and beneficiation, therefore, the as-mined iron ore collected from Karak region of KP has been characterized for its phase, microstructure and chemical composition via XRD, SEM and EDS respectively. Beneficiation of the iron ore has been carried out by shaking table and magnetic separator. XRD analysis confirmed the presence of iron oxide $\left(\mathrm{Fe}_{2} \mathrm{O}_{3}\right)$ as the major phase along with quartz $\left(\mathrm{SiO}_{2}\right)$ as the minor phase. Finely grinded iron ore powder of $100(149 \mu \mathrm{m})$ and $200(74 \mu \mathrm{m})$ mesh sizes were passed via shaking table and magnetic separator subsequently. The iron ore was successfully upgraded from $28.27 \mathrm{wt} . \%$ to $36.51 \mathrm{wt} . \%$ at 100 mesh and $38.70 \mathrm{wt} . \%$ at 200 mesh via shaking table, thus achieving a maximum of $10 \%$ upgraded iron ore. The magnetic separator did not become so effective due to nonmagnetic nature of hematite.
\end{abstract}

Keywords: iron ore, shaking table, microstructure, phase, minor magnetic seprator

\section{Introduction}

With increasing global demand of steel and rapid depletion of high grade iron ores, the utilization of lowgrade iron ores acquired much attention in recent years. Complex mineralogy, high content of silica and other gangue minerals are the major difficulties in the processing and use of low grade iron ores. Thus, upgradation of low grade iron ores to remove the gangue minerals and enhance their quality is a major area of research today (Ali 2004; Ali et al., 2003; Abu-zeid 1967). In most of the known iron ore deposits in Pakistan, many deposits are low grade and needs proper beneficiation, so as to produce and fulfill the requirement of the steel making.

Iron ore deposit of Karak (KP) Pakistan is of low grade and the problem in up-grading this ore deposit is twofold. Firstly, it occur as a mixture of hematite and silica, and secondly, the fine dissemination of iron mineral in silica and silicates, which requires fine grinding to obtain adequate degree of liberation of the desired iron mineral and the gangue constituents.

Gravity and magnetic separation are the economical and most commonly used beneficiation techniques recovery of valuables from natural ores (Burt, 1999). Although other techniques i.e. hydrocyclon, jigging, spirals, flotation and magnetic separation partially

*Author for correspondence; E-mail: sajjad2485@yahoo.com replaced the gravity separation method but they have not made it obsolete. Due to the lowcost, ease of operation, and eco-friendly nature, the gravity separation techniques is widely used in mineral beneficiation practices, since it is based on the principle of settling velocities of the constituents of particles in ore (Mukherjee et al., 2006).

The influential factors in the shaking table and jigging techniques that govern the settling velocity of ore particles include the weight (volume and density) of particles, buoyancy and drag forces (Roy, 2009). Being a powerful technique to recover fine particles of the valuable minerals, many researchers investigated the theoretical and experimental performance of shaking table (Mansar et al., 1991; Gaudin, 1987; Shivamohan 1985). Shaking table efficiency has been reported to be high if the difference in specific gravity is high between valuable and gangue minerals (Samykina, 2005). For the beneficiation of iron ore, a single step magnetic separation cab be performed, if the nature of ore is magnetic and the gangue is nonmagnetic. However, if the ore is non-magnetic then a combination of magnetic separation along with gravity separation can be applied (Svoboda, 1994; Svoboda et al,. 1989).

Guney studied the beneficiation of Camdag hematite ore that is composed of limonite-hematite interlocked in each other. Using a combination of gravity separation and high intensity magnetic separation techniques he 
successfully increased the ore grade from $5-7 \%$ in concentrates with $\sim 60 \%$ recovery by both methods (Guney, 2000).

Abouzeid (Abu-zeid, 1967) worked on the beneficiation of El-Gedida iron ore using high intensity magnetic separator. An ore sample containing 51.6\% Fe, 8.76\% $\mathrm{SiO}_{2}$ and $3.06 \% \mathrm{BaO}$ was studied and successfully point out that high intensity magnetic separator was limited to ore size of 2 and $0.125 \mathrm{~mm}$. The final magnetic product assayed $61 \% \mathrm{Fe}$ at an iron recovery of $90.3 \%$. However, $5 \%$ by weight was obtained as middling assaying $31.4 \% \mathrm{Fe}$. These middling products, together with the fine fraction minus $0.125 \mathrm{~mm}$ which constitute $35 \%$ by weight of the whole sample, were not possible to be upgraded by magnetic separation.

Rowayshed (Rowayshed, 1983) investigated the beneficiation of El-Gedida iron ores using high intensity magnetic separator with limit up to $2 \mathrm{~mm}$ and concluded that neither the coarse nor the very fine sizes of ores can be treated using this technique. The dominant iron minerals present in this ore are the hydrated minerals, goethite and hydro-goethite, which are difficult to treat through high intensity magnetic separator. (Fatma et al., 1999) studied the beneficiation of iron ore sample containing $44 \% \mathrm{Fe}, 1.59 \% \mathrm{SiO}_{2}$ and $20 \% \mathrm{BaO}$ using magnetic separation. After cleaning several times an iron concentrate assaying $58.48 \% \mathrm{Fe}$, and $0.73 \% \mathrm{BaO}$ is obtained. Faraghaly in 2002 studied an iron ore containing $23.5 \% \mathrm{Fe}$ and $34 \% \mathrm{BaO}$. The beneficiation of iron ore was carried out using a dry high intensity magnetic separator and found a concentrate containing $56.78 \% \mathrm{Fe}$ and $1.61 \% \mathrm{BaO}$ at a recovery of $82.76 \%$.

According to the Geological Survey of Pakistan (GSP) the total estimated reserves of different grades of iron ore in Pakistan are $>1.5$ billion tons; however, there is only $\sim 30,000$ tons/year capacity for commercial mining. With further exploration, in depth geological study and appropriate mining techniques a medium scale steel plant can be installed using the local iron ore to fulfill the steel demand of the country (Shah et al., 2004; Kazmi et al., 2001; Siddiqui et al., 2000).

The major aim of this study was to investigate phase, microstructure and possible up-gradation of low-grade iron ore of Karak region via gravity and magnetic separation. The sieve parameters of 100 and 200 mesh sizes of iron ore were investigated through shaking table (exploiting the difference in specific gravity of the constituents in ore) and magnetic separator (exploiting the differences in magnetic susceptibility of the constituents in ore) were investigated.

\section{Materials and Methods}

The representative sample was collected from active mines of iron of Karak region, Khyber Pakhtunkhwa (KP), Pakistan. The sample was washed, dried and ground using a stainless steel mortar and pestle in Materials Research Laboratory (MRL), University of Peshawar. The powdered sample was sieved through $100(149 \mu \mathrm{m})$ and 200 mesh $(74 \mu \mathrm{m})$ size according to the US standards in MRL. A JEOL 3532, X-ray diffractometer with $\mathrm{Cu} K \alpha(\lambda \sim 1.54 \AA)$ radiations operating at $40 \mathrm{KV}$ and $30 \mathrm{~mA}$ at Centralized Resource Laboratory (CRL) was used for phase analysis. For microstructural analysis, $\sim 4 \times 4 \times 4 \mathrm{~mm}^{3}$ piece was cut from iron ore sample with a TeckCut 4TM precision low speed diamond saw (Allied High Tech. Products, USA) in MRL. The sample was finely polished with a TwinPrep 3TM grinding/polishing machine (Allied High Tech Product, USA) using various grades of sandpaper (silicon carbide) and diamond paste on imperial adhesive back polishing cloth using water as a lubricant in MRL. The smooth polished surfaces were chemically etched in $40 \%$ hydrofluoric acid (HF) fumes for one minute. For SEM, the polished sample was mounted onto aluminum stub with silver paint and gold-coated to avoid charging in the SEM. The surface morphology and approximate size of the grains and micro-regions were examined using a JEOL JSM 5910 SEM. Elemental analysis were carried out using energy dispersive Xray electron spectroscopy (EDS) coupled with SEM. A PMG-3 microscope coupled with a DP-12 CCD camera, Olympus (Japan) was used for recording optical images in the present study at CRL. For physical beneficiation via shaking table and magnetic separator, $\sim 100 \mathrm{Kg}$ iron ore was crushed in jaw and roller crushers and grinded in a ball mill to get fine powder up to 100 and 200 mesh at the Multipurpose Mineral and Metallic Ore Upgradation Plant (MPMMOUP), Department of Physics, University of Peshawar.

The shaking table surface is made of $2 \mathrm{~mm}$ thick fibre glass with dimensions of chassis length $(2450 \mathrm{~mm})$ and width $(1200 \mathrm{~mm})$ connected with an adjustable variable speed induction motor $(0.75 \mathrm{KW} / 1 \mathrm{Hp})$ to generate back and forth movement and shake the table surface. Height of shaking table from floor surface depends on the angle of the table. The magnetic separator used in present study consists of a permanent cylindrical magnet 
of $300 \mathrm{~mm}$ diameters and $460 \mathrm{~mm}$ length driven by a $0.75 \mathrm{KW} / 1 \mathrm{Hp}$ induction motor with a speed reducer with a ratio of 1:30. Both the shaking table and magnetic separators were locally manufactured and supplied by Mobashir Engineers, Peshawar.

\section{Results and Discusssion}

Figure 1 shows room temperature XRD pattern of the as-mined iron ore. The inter planer spacing (d-values) and relative intensities corresponding to the major XRD peak recorded for iron ore matched PDF \# 5-490 for quartz of silicon oxide $\mathrm{SiO}_{2}$ indicating to be major phase in the examined sample.

Additionally some peaks matched PDF \# 6 - 502 for Iron Oxide $\mathrm{Fe}_{2} \mathrm{O}_{3}$ (Hematite) with main peaks appearing at $2 \theta$ of $33^{\circ}, 36^{\circ}, 56^{\circ}$ and $68^{\circ}$ as shown in Figure. Some peaks appeared to overlap with each other at $2 \theta$ of $36^{\circ}$, $56^{\circ}$ and $68^{\circ}$. The experimental d-values and intensities of the as-mined iron ore is given in Table 1.

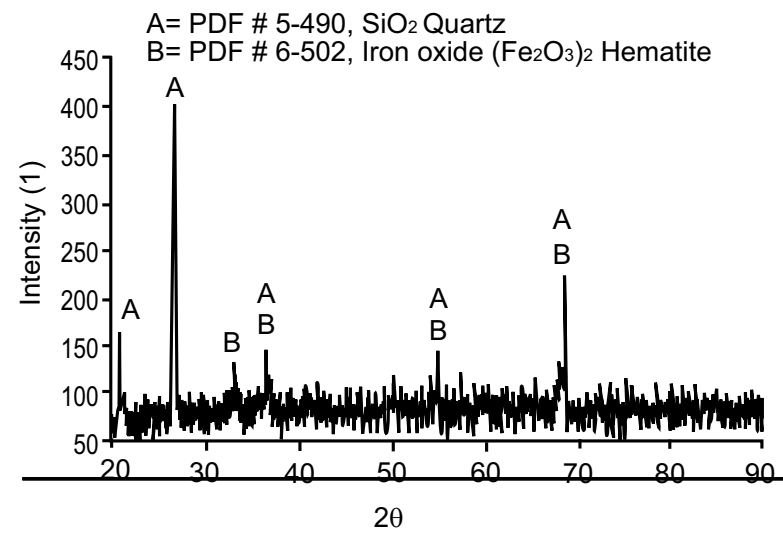

Fig. 1. XRD pattern of as-mined iron ore showing presence of Quartz (labeled as A) as the major phase along with iron oxide (Hematite) as minor phase (B).
The microstructure and the distribution of the impurities within the matrix of iron ore was investigated and analysed using reflected light optical microscopy and scanning electron microscopy (SEM). Figure 2 shows the reflected light micrograph of chemically etched (40 $\%$ HF fumes for $50 \mathrm{sec}$ ) iron ore sample showing the presence of three contrasted microregions with different texture and appearance. The micro region with dark grey texture comprising quartz, appearing as a plane and smooth surface with crystalline plates of irregular shapes (marked as " $A$ ") with size ranging from 10-70 $\mathrm{mm}$. The rough microregion with whitish appearance is Hematite matrix (marked as " $\mathrm{B}$ ") and is very finely immersed along the grain boundary and cracks of the large platy type silica grains. The hematite grains are very finely immersed though out the matrix and the

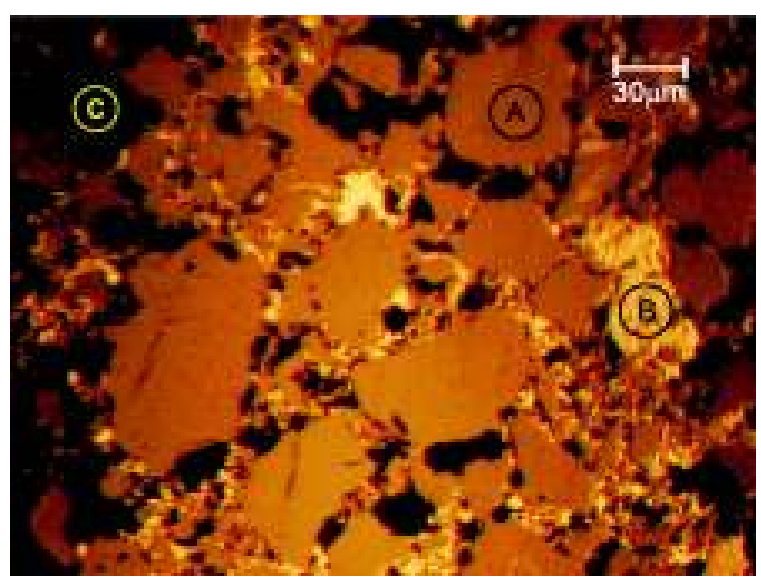

Fig. 2. Reflected light micrograph of iron ore showing dark grey quartz micro-region marked as "A", the rough micro-region with whitish contrast of hematite marked as "B" and black opaque contrast of magnetite marked as "C".

Table 1. comparison of d-value and relative intensity for observed XRD pattern of as-mined iron ore

\begin{tabular}{|c|c|c|c|c|c|c|c|}
\hline \multicolumn{2}{|c|}{ Iron ore sample } & \multicolumn{3}{|c|}{ PDF \# 5- 490, $\mathrm{SiO}_{2}$ Quartz } & \multicolumn{3}{|c|}{ PDF \# 6- 502, Iron oxide (Fe2O3), Hematite } \\
\hline d-value & I/Io & d-value & I/Io & $(\mathrm{hkl})$ & d-value & I/Io & $(\mathrm{hkl})$ \\
\hline 3.34 & 100 & 3.34 & 100 & $(101)$ & -------- & ------- & \\
\hline 4.28 & 25 & 4.26 & 35 & $(100)$ & ------- & ------- & \\
\hline 2.70 & 23 & ------- & ----- & & 2.69 & 100 & $(104)$ \\
\hline 2.46 & 27 & 2.45 & 12 & $(110)$ & 2.51 & 80 & $(113)$ \\
\hline 1.67 & 26 & 1.67 & 7 & $(202)$ & 1.69 & 80 & $(110)$ \\
\hline 1.36 & 49 & 1.37 & 11 & (203) & 1.38 & 20 & $(100)$ \\
\hline
\end{tabular}


grain size ranges from $5-25 \mathrm{~mm}$. The blackish and opaque grains of roughly rectangular and rounded shape may appear to be magnetite (marked as "C"), with an average grain size to be $\sim 15 \mu \mathrm{m}$ (Miaha et al., 2009).

All the three type morphologies are non-uniformly immersed among each other with no clear boundaries among them. Since the average size of the identified hematite grain is $\sim 50 \mu \mathrm{m}$ as clear in the Fig. which showed that the representative iron ore must be crushed to a mesh size of $\sim 300(47 \mu \mathrm{m})$ in order to unlock the hematite grains from the gangue.

Figure 3 shows the secondary electron SEM image (SEI) of as-mined iron ore sample demonstrated the presence of two distinct microregions i.e. plane microregion with grey contrast and rough microregion with whitish contrast. The grey plane microregion with platy type morphology of large irregular shape labeled as " $\mathrm{A}$ " is quartz. The average size of the quartz is $\sim 30$ $\mathrm{mm}$, with grains ranges in size from $10-90 \mu \mathrm{m}$. The rough and granular type white microregion/grains labeled as " $\mathrm{B}$ " is hematite. The hematite grains are observed to be irregular in shape with an average size of $\sim 50 \mu \mathrm{m}$. They appeared to be along the grain boundary of the quartz grains and seemed to interlock these grains. The alternated layers of hematite and quartz with microfolds and faulted features dissecting each other can be clearly viewed in the SEM micrograph. The concentration of iron is more or less uniform in hematite layer. From SEM image, the ore shows a complex sort of interlocking between quartz and hematite. Nirlipta et al., 2013 observed that in such type of iron ores the hematite phase is of secondary origin and form a Martite phase due to the oxidation of magnetite.

A well crystalline formation of the three phases i.e. martite, hematite and quartz occur in such ores. However, hematite which occurs as Martite is pseudomorphic magnetite and it retains the shape of an original magnetite. From geological point of view the transformation of one mineral phase to another occurs due to variation in heat, temperature and pressure that causes the homogeneous crystallization and eventually small crystals are formed by re-crystallization in a large number. Bhattacharya et al., (2007) during their investigation confirmed that hydrothermal fluids caused the re-crystallization of hematite and due to oxidation magnetite gets converted to hematite and then appeared in the form of martitized product. SEM pattern shows presence of acicular hematite with interstitial spaces
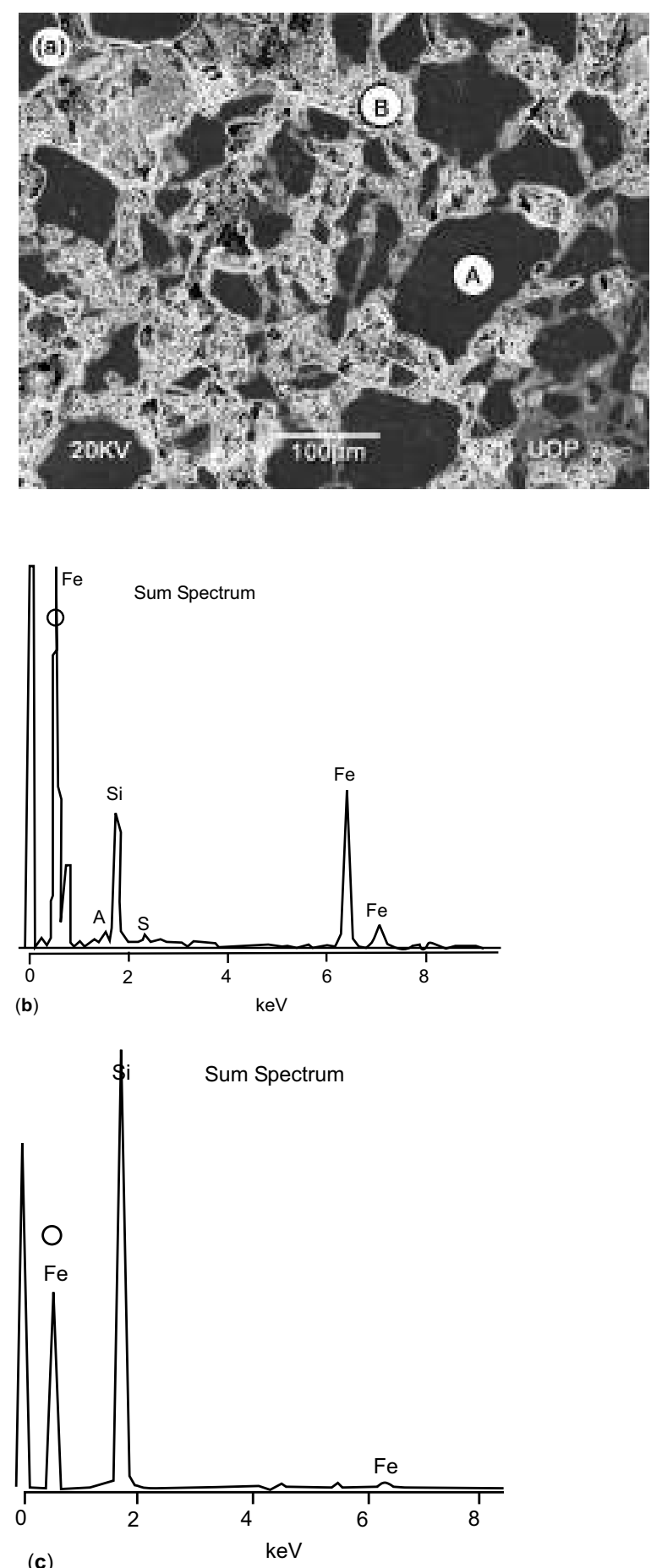

(c)

Fig. 3. (a) SEI of the as-mined iron ore sample showing the presence of Quartz with blakish contrast and plan morphology marked as "A" along with Hematite with white contrast and rough granular morphology marked as "B", (b) EDS spectra of the marked regions B (c) EDS spectrum of the marked region $\mathrm{A}$. 
occupied by quartz. EDX analysis shows a high percentage of $\mathrm{Si}$ (71 wt.\%) and complex interlocking of hematite and silica which made it very difficult for beneficiation. The detailed elemental and relevant oxide composition of the gross and marked micro-regions shown in Fig. 3 is given in Table 2.

EDS analysis showed the presence of high concentration of iron in rough granular micro-regions marked as ' $\mathrm{B}$ ' and high concentration of silicon in the microregion with black contrast marked as ' $\mathrm{A}$ '.

Beneficiation of iron ore via shaking table. EDS spectra of the concentrate obtained from shaking table for iron ore at 100 and 200 mesh sizes are shown in Fig. 4 (a, b). The gross elemental and oxide compositions for 100 and 200 meshes are given in Table 3.

Table 2. Elemental and oxide composition of different micro-regions shown in Fig. 3.

\begin{tabular}{lllllll}
$\begin{array}{l}\text { Micro- } \\
\text { region/ } \\
\text { grain }\end{array}$ & $\begin{array}{l}\text { Elemental } \\
\text { composition } \\
\text { (wt.\%) }\end{array}$ & & & \multicolumn{3}{l}{ Oxide composition (wt.\%) } \\
\cline { 2 - 3 } \cline { 5 - 7 } & $\mathrm{Fe}$ & $\mathrm{Si}$ & & $\mathrm{O}$ & $\mathrm{Fe}_{2} \mathrm{O}_{3}$ & $\mathrm{SiO}_{2}$ \\
\hline Gross & 23.37 & 39.64 & & 36.99 & 28.27 & 71.73 \\
$\mathrm{~A}$ & $\ldots .$. & 99.99 & & --- & --- & 100 \\
$\mathrm{~B}$ & 71.12 & 8.35 & & 20.53 & 85.06 & 14.94
\end{tabular}
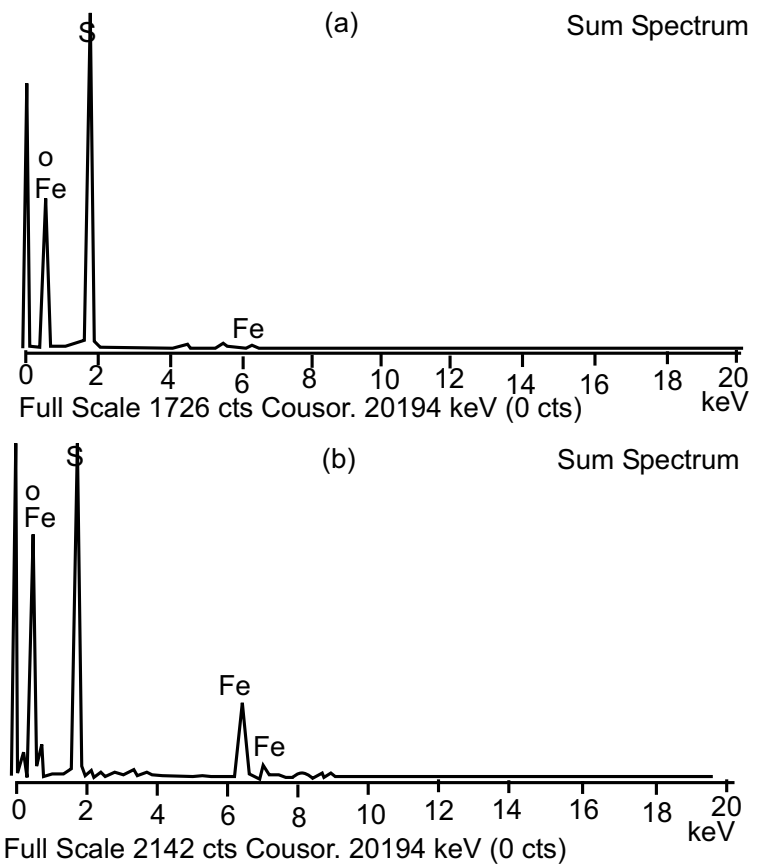

Fig. 4. $(a, b)$ : EDS spectra of iron ore after passing via shaking table at 100 and 200 meshes.
EDS study confirmed the concentration of iron in the as-mined ore sample to be $23.37 \mathrm{wt} \%$ and after beneficiation through shaking table at 100 and 200 mesh it was 36.51 and $38.70 \mathrm{wt} . \%$ respectively indicating an increase in the concentration after beneficiation. Similarly the content of silica decreased from 39 to 27 wt. \%. A comparison of oxide concentration of iron and silica before and after beneficiation is shown in Table 4. Figure 5 shows as increase in concentration of iron and decrease of silica by increasing mesh size from 100 to 200 mesh.

From these results it can be conclude that by reducing particle size of ore the concentration of iron increases and that of silica decreases and more beneficiation will take place. It indicates that minerals begin to separate into iron and silica after 100 mesh particle size due to differences in density. But economically it is not fruitful due to high energy consumption for getting fine particle size. Isnugroho et.al. (2011) observed that the process of iron mineral separation from concern gangue will be higher with increasing level of fine particle size. Passing the ore through magnetic separator brings no upgradation because of non-magnetic nature of hematite

Table 3. Elemental and oxide composition of iron ore concentrate obtained from shaking table at 100 and 200 mesh sizes.

\begin{tabular}{|c|c|c|c|c|c|}
\hline \multirow{4}{*}{$\begin{array}{l}\begin{array}{l}\text { Mesh } \\
\text { size }\end{array} \\
100 \\
\mathrm{Fe}_{2} \mathrm{O}_{3}\end{array}$} & \multicolumn{5}{|c|}{ Gross elemental and oxide composition (wt. \%) } \\
\hline & \multicolumn{3}{|c|}{ Elements } & \multicolumn{2}{|c|}{ Oxide } \\
\hline & $\mathrm{Fe}$ & $\mathrm{Si}$ & & $\mathrm{O}$ & \\
\hline & $\mathrm{SiO}_{2}$ & & & & \\
\hline & 23.50 & 27.30 & 49.20 & 36.51 & 63.49 \\
\hline 200 & 25.90 & 25.06 & 49.04 & 38.70 & 61.30 \\
\hline
\end{tabular}

Table 4. Comparison of iron oxide and silica content in the as-mined ore and after beneficiation via shaking table at 100 and 200 mesh sizes.

\begin{tabular}{|c|c|c|c|c|}
\hline $\begin{array}{l}\text { Gross oxide } \\
\text { of as- } \\
\text { composition } \\
\text { mined iron } \\
\text { ore }\end{array}$ & \multicolumn{2}{|c|}{$\begin{array}{l}\text { Oxide composition } \\
\text { of iron ore at } 100 \\
\text { mesh }(149 \mu \mathrm{m}) \text { after } \\
\text { beneficiation via } \\
\text { shaking table }\end{array}$} & \multicolumn{2}{|c|}{$\begin{array}{l}\text { Oxide composition } \\
\text { of iron ore at } 200 \\
\text { mesh }(74 \mu \mathrm{m}) \text { after } \\
\text { beneficiation via } \\
\text { shaking table }\end{array}$} \\
\hline Oxides $\quad w t \%$ & Oxide & $\mathrm{wt} \%$ & Oxide & w t $\%$ \\
\hline 28.26 & $\mathrm{Fe}_{2} \mathrm{O}_{3}$ & 36.51 & $\mathrm{Fe}_{2} \mathrm{O}_{3}$ & 38.70 \\
\hline 71.73 & $\mathrm{SiO}_{2}$ & 63.49 & $\mathrm{SiO}_{2}$ & 61.30 \\
\hline
\end{tabular}




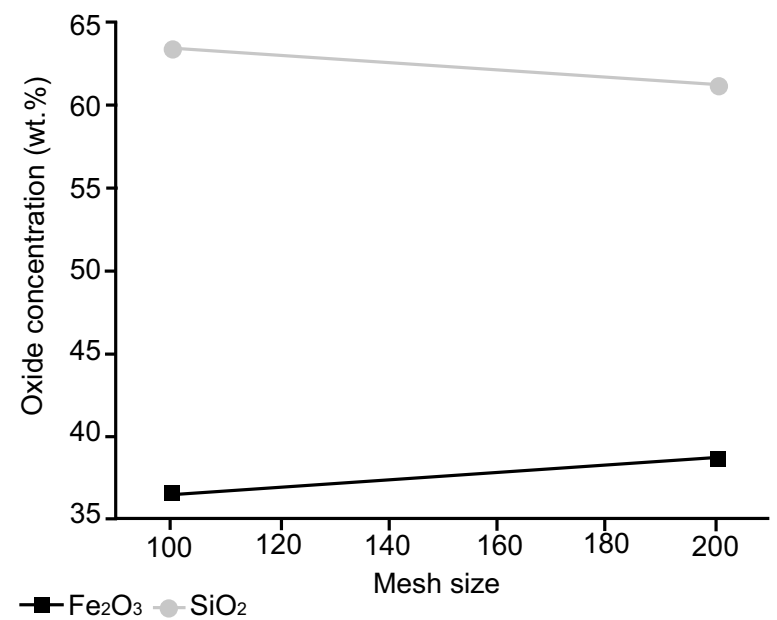

Fig. 5. Variation of the oxide concentration of iron and silica with mesh size, indicating an increase in the iron oxide content and decrease in silica content.

ore. The nonmagnetic iron ore can be changed into a magnetic iron ore through roasting.

\section{Conclusion}

In this research work iron ore from Karak, KP, Pakistan was characterized using XRD, SEM and RLM. Karak iron ore is a low grade siliceous iron ore. The major elements detected by EDS in this ore are Iron and silicon. From XRD the presence of iron oxide (Hematite) and silica phases were identified. The up-gradation/ beneficiation of iron ore was performed using shaking table and magnetic separator. Through shaking table the iron ore was up-graded from $28.27 \mathrm{wt} . \%$ to 38.70 wt. $\%$ at 200 mesh, thus achieving a maximum of $10 \%$ upgraded ore. Due to non-magnetic nature of the ore the technique of magnetic separation was proved to be ineffective.

\section{Acknowledgement}

The authors acknowledge the financial support of Higher Education Commission (HEC), Pakistan. The authors also acknowledge the financial support of the Khyber Pakhtunkhwa Government through the Pilot Research Studies Program of the Directorate of Science \& Technology (DoST), KP for extension in the Mineral Up- gradation Pilot Plant and Up-gradation of Materials Research Laboratory, University of Peshawar, Pakistan.

Conflict of Interest. The authors declare no conflict of interest

\section{References}

Abu-zeid, A.M. 1967. A Contribution to the Beneficiation of El-Gedida Iron ore, Bahariya Oases, Egyp, M.Sc. Thesis, 60-62pp Faculty of Engineering, Cairo University page.

Ali, M.N.W. 2004. A study on the oolitic iron ore mineralization of wadi halfa, Arab Mining Conference, University of Amman, Jorden.

Ali, M. N.W., Babiker, M.E., Eltayeb, H., Haroun, A. 2003. A study on the oolitic iron ore mineralization of wadi halfa, Arab Mini Conference Geolocal Research Authority of Sudan.

Bhattacharya, H.N., Chakraborty, I. Ghosh, K.K. 2007. Geochemistry of some banded iron formations of the Archean supracrustals, Jharkhand-Orissa region, India. Journal of Earth Systems Science, 116: 3, 245-259.

Burt. R. 1999. The role of gravity concentration in modern processing plants, Minerals Engineering 12: 1291-1300.

Fatma, H.A., Arafa, M.A. 1999. Concentrate from an egyptian baritic iron ore. Proceedings of the $6^{\text {th }}$ International Conference on Mining, Petroleum, and Metallurgy, Faculty of Engineering, Cairo University, 1999.

Faraghaly, M.G. 2002. Beneficiation of el-gedida barite iron ore, Journal of Engineering Science, 30: 779-812.

Gaudin, A.M. 1987. Principles of Mineral Dressing, Tata Mcgraw-Hill Publishing Company Limited, Mohan Makhijani at Rekha Printers pvt. ltd, New Delhi, India.

Guney, A. 2000. The beneficiation of camdag iron ore, ITU, Mining Eng. Dep. Min and Coal processing Section, 80626, Maslak, Istanbul, Turkey.

Isnugroho, K., Birawidha, D.C. 2011. Beneficiation of low grade iron ore with manganese content as raw material for ferro. Mineral Processing Division Indonesian Institute of Science (LIPI),

Kazmi, A.H., Abbas, S.G. 2001. Metallogeny and Mineral Deposits of Pakistan. pp. 47-58 Graphic Pulisher, Karachi.

Mansar, R.J., Barley, R.W., Wills, B.A. 1991. The shaking table concentrator the influence of operating conditions and table parameters on mineral separation the development of a mathematical model for normal operating conditions, Minerals Engineering, 4: 369-381. 
Miaha, P.P., Mohapatara, B.K., Mahanta, K. 2009. Upgradation of low grade siliceous manganese ore from Bonai-Keonjhar belt, Orrisa, India, Journal of Minerals and Materials Characterization and Engineering, 8: 47-56.

Mukherjee, A.K., Bhattacharjee, D., Mishra, B.K. 2006. Role of water velocity for efficient jigging of iron ore, Minerals Engineering, 19: 952-959.

Nirlipta. P.N. 2013. Mineralogical constraints in beneficiation of low grade iron ores of barsua, eastern India, International Journal of Engineering and Innovative Technology (IJEIT) 3: 109.

Roy, S. 2009. Recovery improvement of fine iron ore particles by multigravity separation. The Open Mineral Processing Journal, 2: 17-30.

Rowayshed, S.A. 1983. "Beneficiation of El-bahariya Oasis Low Grade Iron Ores", M.Sc. Thesis, Faculty of Engineering, Al-azhar University, Cairo, 103.

Samykina, E., Surkov, A., Eppelbaum, L., Semenov, S. 2005. Do old spoils contain large amounts of economic minerals? Minerals Engineering, 18: 643-645.

Shah, M.T., Moon, C.J. 2004. Mineralogy, geochemistry and genesis of the ferromanganese ores from Hazara area, NW Himalayas, northern Pakistan. Journal of Asian Earth Sciences, 23: 1-15.

Shivamohan, R., Forssberg, E. 1985. Principles of tabling, International Journal of Mineral Processing, 15: 281-295.

Siddiqui, R.H., Naghma, H.S., Ghazanfar, A. Kakepoto, A.A. 2000. Mineralogy and gensis of dilbnad iron ore Balochistan, Pakistan, Geolgica, Geoscience Laboratory'. Geologica, Islamabad Pakistan, Islamabad Pakistan, vol. 5: 67-97.

Svoboda, J., Ross, V.E. 1989. Particle capture in the matrix of magnetic separator, International Journal of Mineral Processing, 27: 75-94.

Svoboda, J. 1994. The effect of magnetic field strength on the efficiency of magnetic separation, Mineral Engineering, 7: 747-757. 